Research Article

\title{
Seismic Performance and Risk Assessment of Traditional Brick-Wood Rural Buildings Based on Numerical Simulation
}

\author{
Baokui Chen (iD, Li Fan, Jingang Xiong, Ming Wen, and Yaru Liu \\ School of Civil Engineering and Architecture, Nanchang University, Nanchang 33031, China \\ Correspondence should be addressed to Baokui Chen; baokui_2000@163.com
}

Received 22 April 2021; Revised 31 May 2021; Accepted 16 June 2021; Published 19 July 2021

Academic Editor: Meng Gao

Copyright (C) 2021 Baokui Chen et al. This is an open access article distributed under the Creative Commons Attribution License, which permits unrestricted use, distribution, and reproduction in any medium, provided the original work is properly cited.

\begin{abstract}
The recent earthquakes have caused serious damage to Chinese rural houses. Research on the seismic performance and reinforcement for traditional rural houses is strongly needed. In this study, the seismic performance of traditional brick-wood structural houses in Jiangxi province and surrounding areas is analyzed and confirmed by site investigation and numerical simulation. And, the traditional constructions, such as the purlin roof and the cavity wall, are considered. These construction types can reduce the seismic behavior of rural houses, and limited research has been carried out. This study found that the structure will produce plastic deformation and local damage above 6-degree earthquake fortification action. The damage positions occurred in the walls close to purlins and the walls close to doors and windows. Given the above seismic safety problems, a reinforcement method of reinforced cement mortar strip and mesh surface is proposed, which is suitable for engineering applications for traditional rural houses. The seismic strengthening effect is analyzed by numerical simulation. Comparing the calculation results, it is found that the seismic performance of the structure after reinforcement is significantly enhanced, and the stress concentration of the walls is improved.
\end{abstract}

\section{Introduction}

Currently, there are many problems in rural buildings in China, such as unreasonable structural design and nonstandard construction. There is a great earthquake risk due to a lack of corresponding seismic design code for rural houses. Different from urban buildings, the structural types of traditional rural buildings have obvious regional characteristics and unique styles. The seismic performance and safety problems of rural houses from the different areas are distinct. Therefore, the research on seismic performance of regional rural buildings and the seismic reinforcement methods of existing rural houses need to be supplemented urgently.

At the same time, it was found that the unreinforced masonry structure could not withstand the test of large earthquakes through the damage to the Xingtai earthquake in 1966, the Tangshan earthquake in 1976, and the Wenchuan earthquake in 2008. In particular, the self-built masonry structured houses in rural areas were seriously damaged. For example, the walls of rural masonry buildings in the Wenchuan earthquake cracked a lot and even partially collapsed [1]. In the 8-degree area, most of the old rural houses were damaged, and some collapsed. Above the 6degree area, most of the rural masonry buildings were seriously damaged or collapsed [2]. However, for areas with low fortification intensity and lack of seismic fortification awareness and measures, even under the action of medium and small earthquakes, the traditional rural buildings will be seriously damaged. For example, in 2005, regarding the Jiujiang earthquake with Ms5.7, the traditional brick-wood structured houses were severely damaged, with a damage ratio of $48.61 \%$ and a medium damage ratio of $26.22 \%$, which was the highest among all kinds of buildings [3]. The traditional brick-wood structured farmhouse is also the main research object of this paper.

At present, the research on seismic performance of masonry structures of China mainly focused on three types of structures, namely, reinforced masonry structure, restrained masonry structure, and reinforced masonry 
structure. Based on the earthquake damage analysis of the Tangshan earthquake, it is generally recognized that the structure of reinforced concrete rang beams and structural columns can effectively increase the deformation capacity of brick masonry buildings, make use of deformation energy, and enhance the seismic capacity of brick buildings, especially the collapse resistant capacity [4]. Based on the restrained masonry structure, researchers also put forward the reinforced masonry structure, and it has been proven by relevant tests [5] that the reinforced masonry has good seismic performance with high strength and strong deformation capacity. The form of masonry structured abroad is quite different from that in China. The main masonry structure is concrete or clay block, and the masonry method is mostly reinforced masonry structure [6-9].

The studies on masonry structure reinforcement methods mainly focus on the reinforcement of masonry walls, including experimental studies on traditional material reinforcement methods, such as adding ring beam to structural column, reinforced by steel bar-mortar [10] and reinforced by steel bar-mortar crossed strip method [11]. Moreover, in recent years, some new material reinforcement methods have been put forward, such as composite fiber sheet reinforcement method [12], high-performance composite mortar with steel mesh strip reinforcement method [13], high ductility fibber reinforced concrete surface layer reinforcement method [14], high strength wire cable mesh and polymeric mortar reinforcement method [15], and high ductility concrete reinforcement structure column restraint method [16]. Generally speaking, there are mature theories about seismic reinforcement of masonry structures, but there is little research on seismic reinforcement of traditional masonry structure buildings in specific areas.

Nowadays, numerical simulation technology has become the main method of structural seismic research. Dynamic analysis of masonry structured models in some cities and towns has been published. Ge et al. [17] used ABAQUS to analyze the seismic performance and collapse risk of old masonry buildings before and after reinforcement. Sun and Deng [18] analyzed the seismic behavior of bottom frame structure building. Hua et al. [19] and Wu et al. [20] analyzed the seismic performance and dynamic characteristics of rural brick-concrete structure buildings. Yu et al. [21] analyzed the effect of masonry strength on seismic performance of self-built dwellings through shaking table tests and numerical simulation method. Zhou et al. [22] analyzed the seismic performance of existing rural masonry buildings. Zhao et al. [23] tried to analyze the seismic vulnerability of rural buildings. The above results are mainly aimed at brickconcrete structured houses, but there are few studies on traditional brick-wood structured houses. Yao et al. [24] conducted seismic elastic-plastic analysis of brick-wood structured farmhouse, found that the strength of mortar has an important impact on the seismic capacity of the structure, and gave the weak spots of the structure. This study mainly focuses on low-rise rural houses in north China, whose structure is different from brick-wood structures in south China, and the cavity wall is not considered.
In summary, to master the seismic safety of traditional brick-wood structured buildings in Jiangxi Province and surrounding areas and cooperate with the national poverty alleviation and rural dilapidated houses reconstruction, this paper, combined with a large number of research studies and finite element numerical analysis, determined the seismic performance and seismic weak spots of this kind of structure and put forward the seismic reinforcement method suitable for this kind of buildings in this region. The seismic performance of the brick-wood structured model before and after reinforcement is compared to further verify the reinforcement effect.

\section{Seismic Performance of Existing Brick-Wood Rural Structures in South China}

The brick-wood rural buildings in Jiangxi were mostly built in the 1970s and 1980s. They are made of ordinary fire brick and built with lime mortar. The thickness of the exterior wall is generally $240 \mathrm{~mm}$, and the interior wall is $120-240 \mathrm{~mm}$. They are generally cavity walls, and there is a mixed-use of fire brick and adobe brick. The wall is high, without a ring beam and structure column. The purlin roof is usually of a double slope structure and consists of small green tiles or glazed tiles.

The survey found that the traditional brick-wood rural buildings in Jiangxi are highly seismic risk, and many safety problems are not conducive to earthquake resistance. First of all, due to the large bay and height of the frame, the bearing walls are generally cavity walls, which causes the load-carrying capacity and stability of the walls to decrease, and the walls are prone to cracking and skewing, which is not conducive to earthquake resistance, as shown in Figure 1. Secondly, there are many masonry quality problems of brick-wood rural buildings, such as the fact that the vertical and horizontal walls are not firmly overlapped, have inadequate mortar, and have mixed masonry of brick masonry and adobe brick (as seen in Figure 2). Thirdly, due to the high wall and unreasonable set of door and window openings, lintels or brick arched lintels are generally not set, resulting in cracks in the wall near the opening, as shown in Figure 3. In addition, the hard mountain purlin structure used in the roof has weak horizontal restraint ability to the house, and the timber purlin and the wall are not firmly connected and cannot form cooperative work between each other (as shown in Figure 4). Under the action of an earthquake, local damage is easy to occur, resulting in an overall collapse of the wall.

Moreover, such buildings have been built for a long time, the materials may be eroded and aged, and most of the existing buildings are still used for living. Therefore, the seismic risk of this kind of buildings is high, and it is easy to cause the loss of family property and even casualties under the action of an earthquake. So, it is urgent to quantify the seismic risk of the building and do seismic reinforcement. 


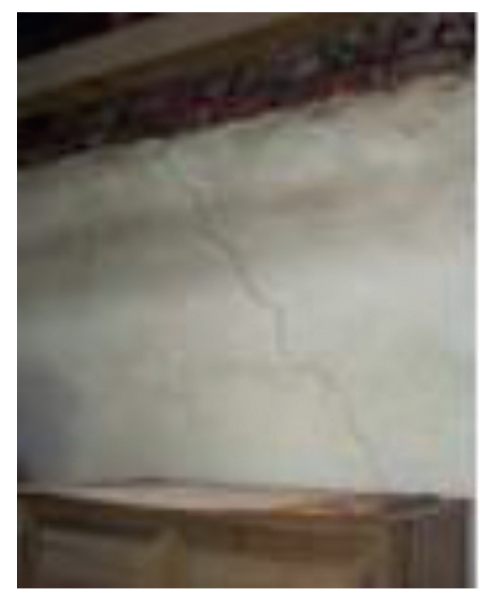

Figure 1: Wall cracks.

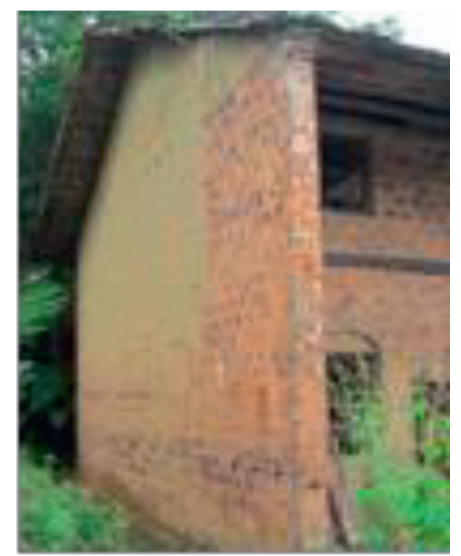

FIgure 2: Mixed masonry method.

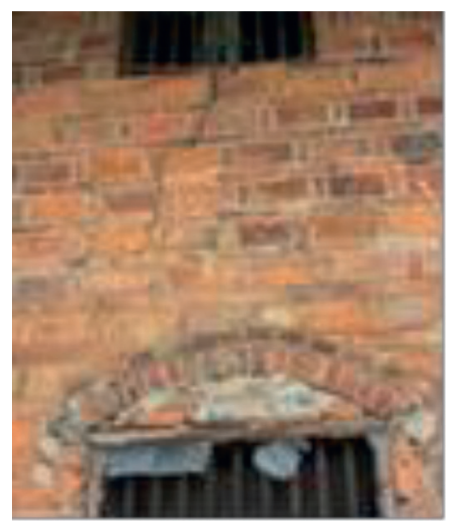

FIGURE 3: Crack in the wall between the windows.

\section{Seismic Performance of Brick-Wood Rural Buildings}

Different from urban buildings, rural houses in China are basically constructed by farmers themselves based on traditional crafts in China, not designed and constructed according to architectural norms. Since there are a large number of self-built bricks and wood houses in rural China,

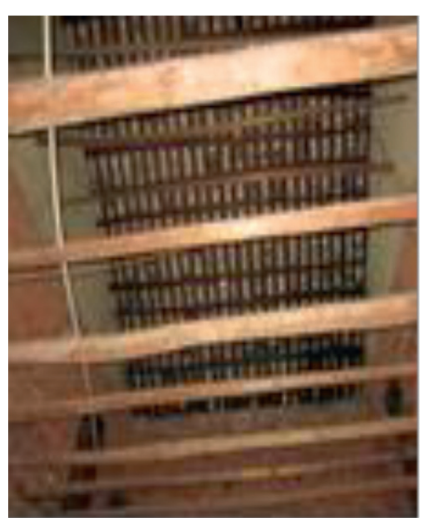

FIgURE 4: Roof truss structure.

these houses often lack the necessary seismic design. Therefore, this paper studies the specific seismic defects of these houses, which proves that this paper has good engineering application value. In addition, the study selected building examples of a household still living in Shangli County, Jiangxi Province. The converted house is a typical brick and wood structured house in the region. The research group has made reinforcement design and field construction with this building as an engineering example.

By using the finite element analysis software ADINA, a refined seismic response analysis model of buildings considering the structure of cavity wall and purlin roof is established. Firstly, through modal analysis, compare the natural vibration period calculated by the finite element model and the empirical formula to verify the rationality of the model. Then, through seismic response analysis, the seismic safety and seismic weak points of the structure under the earthquake action of 6 and 7 degrees are quantified.

3.1. Model Introduction. In this study, a numerical model is established by taking the traditional brick-wood rural buildings in Jiangxi Province as an example. The structure is a 2-story, 3-bay, and 4-room house. The story height is $3.6 \mathrm{~m}$, there is no floor between the stories (it belongs to the common structure of brick-wood rural buildings in Jiangxi Province and surrounding areas), and the cavity wall thickness is $240 \mathrm{~mm}$. The purlin roof is directly laid on the horizontal wall. The purlin diameter is $200 \mathrm{~mm}$, without ring beam and structural column, and the model building design drawing is shown in Figure 5.

3.2. Model Simplification and Parameters. In this paper, the bearing brick wall adopts the overall modelling method to establish the finite element model of the brick-wood structure. In addition, through the equivalent method, the thickness of the model wall is adjusted to $190 \mathrm{~mm}$ to ensure the rationality of the cavity wall modelling, so that the model has the same dynamic characteristics as the original structure and meets the needs of dynamic analysis.

Masonry adopts the masonry constitutive relation expression put forward by Professor Liu [25] of Hunan University, which is shown in formula (1). According to the 


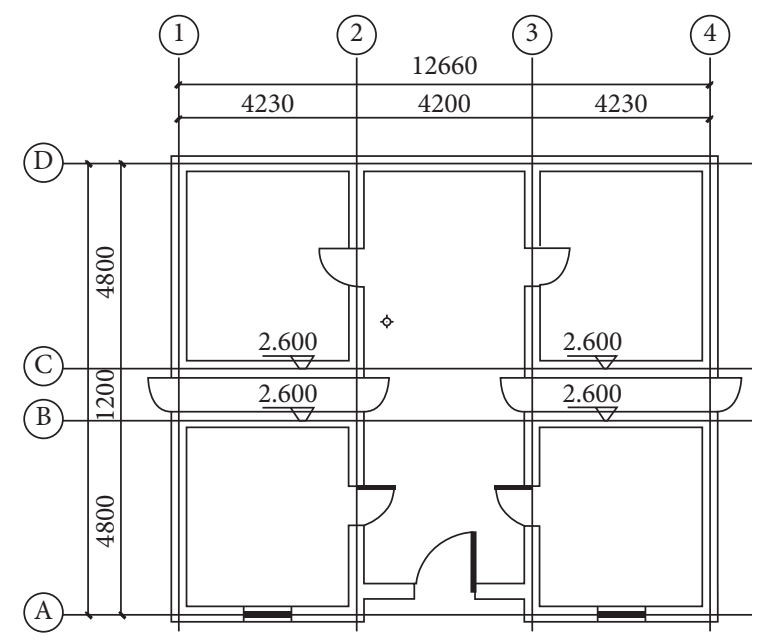

(a)

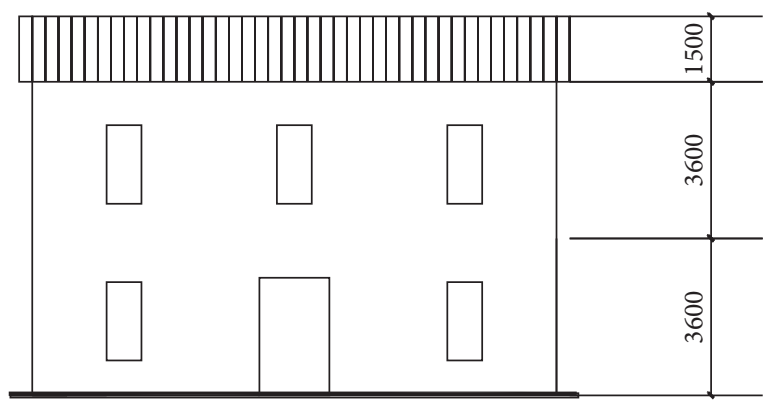

(b)

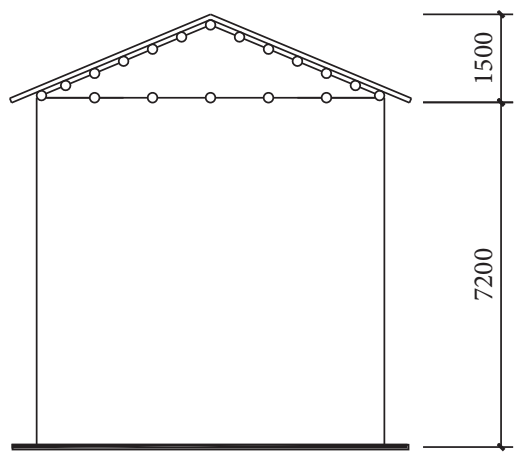

(c)

FIGURE 5: Architectural diagram of brick-wood structural house. (a) Layout plan of an engineering project. (b) Front elevation layout. (c) Model side elevation layout.

code for the design of masonry structures and related literature [26], the basic parameters of masonry materials can be calculated, as shown in Table 1 .

$$
\frac{\sigma_{c}}{f_{m}}= \begin{cases}1.96 \frac{\varepsilon}{\varepsilon_{0}}-0.96\left(\frac{\varepsilon}{\varepsilon_{0}}\right)^{2}, & \frac{\varepsilon}{\varepsilon_{0}} \leq 1, \\ 1.2-0.2 \frac{\varepsilon}{\varepsilon_{0}}, & 1 \leq \frac{\varepsilon}{\varepsilon_{0}} \leq 1.6,\end{cases}
$$

where $\sigma_{c}$ and $\varepsilon$ are the compressive stress and strain of masonry and $f_{m}$ and $\varepsilon_{0}$ are the average axial compressive strength of masonry and their corresponding strain values.

As a natural growth material, the mechanical properties of the wood show obvious anisotropy. At the same time, affected by many factors such as growth environment and varieties, the performance varies greatly. Therefore, this paper adopts the mechanical properties of wood under the general ideal state. According to the relevant literature [27], the basic parameters of timber purlin material are listed in Table 2.

In the table, EL, ER, and ET are, respectively, the elastic modulus ( $\mathrm{MPa}$ ) of the timber purlins parallel to the grain, transverse grain tangential, and transverse grain radial; $\mu \mathrm{TL}$, $\mu \mathrm{RT}$, and $\mu \mathrm{LR}$ are, respectively, the Poisson ratios (MPa) of
TABLE 1: Basic parameters of masonry materials.

\begin{tabular}{lcc}
\hline Elastic modulus $(\mathrm{MPa})$ & Poisson ratio & Density $\left(\mathrm{kg} / \mathrm{m}^{3}\right)$ \\
\hline 2218 & 0.15 & 2000 \\
\hline
\end{tabular}

TABLE 2: Basic parameters of timber purlin material.

\begin{tabular}{lcccccccc}
\hline EL & ER & ET & $\mu \mathrm{TL}$ & $\mu \mathrm{RT}$ & $\mu \mathrm{LR}$ & GLR & GRT & GTL \\
\hline 1955 & 9702 & 1955 & 0.52 & 0.352 & 0.106 & 971 & 218 & 609 \\
\hline
\end{tabular}

the timber purlin's parallel to grain radial, transverse grain tangential, and transverse grain radial; GLR, GRT, and GTL are, respectively, the shear modulus $(\mathrm{MPa})$ of the timber purlin's longitudinal and tangential, radial and longitudinal, and tangential and radial.

3.3. Seismic Waves. Earthquake has great randomness. Under different seismic wave actions, the actual responses of the structure have obvious difference, so the seismic wave should be selected reasonably for analysis. The selection of seismic wave is mainly based on factors such as peak acceleration, duration, spectrum characteristics, and site conditions. The selected period of seismic wave should be close to the site characteristic period. At the same time, the 


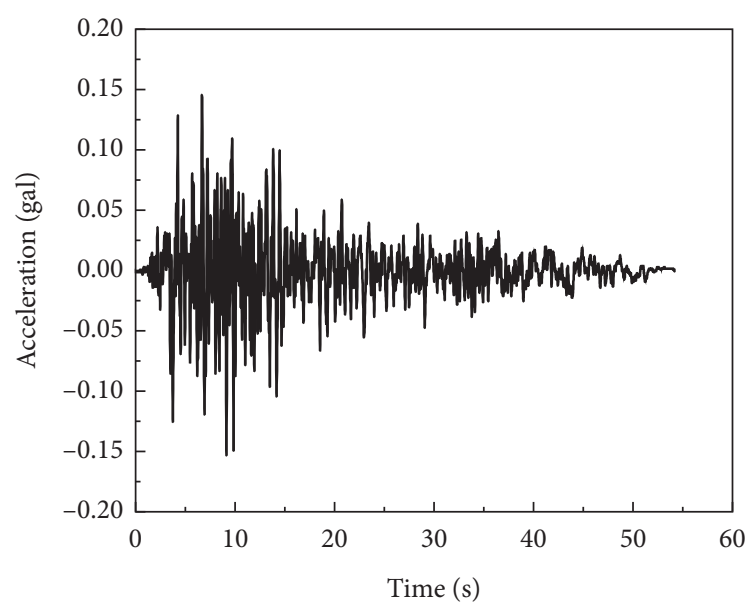

(a)

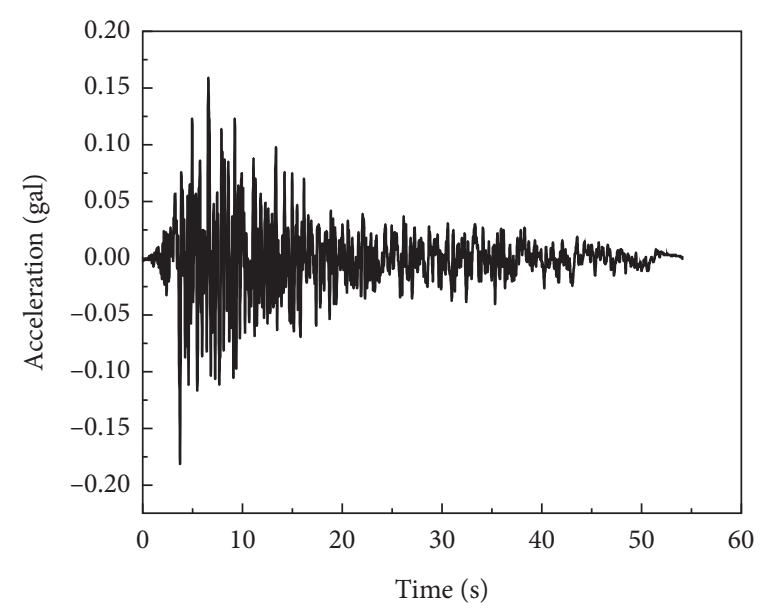

(b)

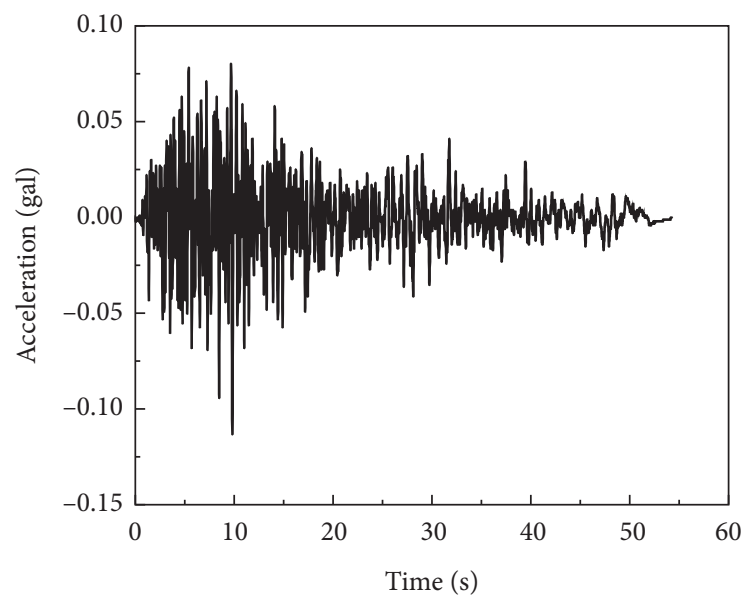

(c)

Figure 6: Taft wave source record. (a) X-direction. (b) $Y$-direction. (c) Z-direction.

reasonable duration of seismic wave is easy to cause the structure to be damaged by plastic deformation accumulation, so as to achieve the purpose of analysis. In addition, when the peak acceleration of the original seismic wave does not meet the requirements of the relevant codes or analysis needs, the seismic wave size should be adjusted proportionally.

In this paper, the site classification of brick-wood structure is class II, the classification of design earthquake is the first group, and seismic fortification intensity is 6 (7) degrees (only some areas in Jiangxi Province have seismic fortification intensity of 7 degrees). According to the above conditions, the Taft wave, EL-Centro wave, and Loma Prieta seismic wave are selected in this paper. Each seismic wave is intercepted at $12 \mathrm{~s}$, the seismic wave is calculated according to the peak acceleration of 6 and 7 degrees, and the original acceleration record of Taft wave is shown in Figure 6.

The so-called "standard" in the standard seismic wave means that its response spectrum is more consistent with the code design spectrum or the "average spectrum" of multiple earthquakes. Therefore, it has many applications in the field of earthquake engineering. Among them, the spectra of ELCentro wave and Taft wave combined with the "average spectrum" are similar. Take the EL-Centro wave as an example and compare it with the average spectrum of 20 earthquakes as shown in Figure 7: comparison of EL-Centro wave and average spectrum of 20 earthquakes.

\subsection{Numerical Results}

3.4.1. Modal Analysis. Through modal analysis, the first 6 natural vibration periods of the structure are obtained, as shown in Table 3.

Yang et al. [28] put forward the empirical formula of the basic period of masonry structure, and the formula is as follows:

$$
T_{1}=0.0168\left(H_{0}+1.2\right),
$$

where $T_{1}$ is the basic period and $H_{0}$ is the height of the structure. According to empirical formula (2), $T 1=0.0168 \times(7.2+1.2)=0.141 \mathrm{~s}$, which is close to the numerical simulation results with an error of less than $5 \%$, proving that the brick-wood structure model is reasonable.

Different from other structures $[29,30]$, the shaking table tests of the brick-wood structured houses studied in 


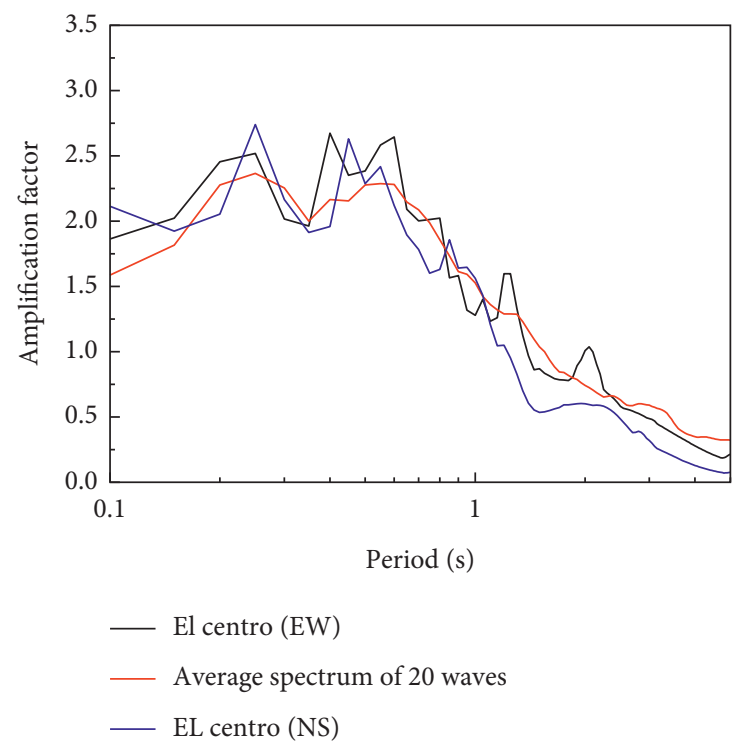

Figure 7: Comparison of the EL-Centro seismic response spectrum and the average spectrum of 20 seismic waves on medium-hard soil sites.

TABle 3: The first 6 natural vibration periods of brick-wood structure.

\begin{tabular}{lcccccc}
\hline Vibration & $\begin{array}{c}1 \\
\text { order }\end{array}$ & $\begin{array}{c}2 \\
\text { order }\end{array}$ & $\begin{array}{c}3 \\
\text { order }\end{array}$ & $\begin{array}{c}4 \\
\text { order }\end{array}$ & $\begin{array}{c}5 \\
\text { order }\end{array}$ & $\begin{array}{c}6 \\
\text { order }\end{array}$ \\
\hline $\begin{array}{l}\text { Frequency } \\
\text { (Hz) }\end{array}$ & 7.285 & 8.029 & 8.382 & 8.656 & 8.876 & 8.929 \\
Period (s) & 0.137 & 0.125 & 0.119 & 0.1169 & 0.113 & 0.112 \\
\hline
\end{tabular}

this research are relatively rare, and the numerical results in this study are compared with the theoretical solution of the natural vibration period of the masonry structure to verify the model.

3.4.2. Displacement Response. Under the action of an earthquake, the displacement response to each floor of the structure is shown in Figures 8-10. The failure degree of the masonry structure of this study takes the interval displacement angle as the evaluation standard, as shown in Table 4. Statistics of the displacement of each floor, the interval displacement angle, and the failure degree of brickwood structured houses in the three earthquakes are shown in Table 5.

According to the structure displacement cloud diagram and the interval displacement angle statistics, it is found that under the action of an earthquake, the maximum displacement in the $Y$ direction of the structure appears in the top of the gable, while the maximum displacement in the $X$ direction occurs in the top of the inner transverse wall and the opening of the second floor. In addition, the displacement response in the $Y$ direction of the structure is significantly greater than that in the $X$-direction. Taking the Taft wave $(0.2 \mathrm{~g})$ as an example, the maximum displacement in the $Y$ direction of the structure is $6.599 \mathrm{~mm}$, the maximum displacement in the $X$ direction is $2.34 \mathrm{~mm}$, and the maximum displacement in the $Y$ direction is 2.82 times that in the $X$-direction. It can be seen that under the action of an earthquake, the purlin roof is not conducive to the seismic resistance of the structure, and the top of the gable is easy to generate a large displacement, and even cause local collapse.

The calculation results of the analysis model show that under the action of a 6-degree earthquake, the structure reached medium damage and the structure has reached serious damage under the action of a 7-degree earthquake. It can be seen that the seismic performance of brick-wood rural buildings is poor, which cannot resist the action of 6 and 7-degrees earthquakes.

At the same time, combined with the cloud diagram, it is found that the structure has a large displacement in the top of the gable, the opening and the top of the inner transverse wall, and it is the weak seismic position, which should be paid attention to as the key reinforcement location.

3.4.3. Stress Response. Under the earthquake loads, the statistics of the maximum shear stress of the wall bottom are shown in Table 6, and the cloud diagram of the maximum main tensile stress of the structure is shown in Figures 11-13.

According to the cloud diagram of the maximum main tensile stress of the structure and the statistics of the maximum shear stress of wall bottom, it can be seen that the main tensile stress of the wall has obvious stress concentration phenomenon in the top of the gable, the opening, the wall between windows, and the intersection of horizontal and vertical walls. The main tensile stress exceeds $0.23 \mathrm{MPa}$ of the clay brick, indicating that the local wall has entered the plastic stage. 


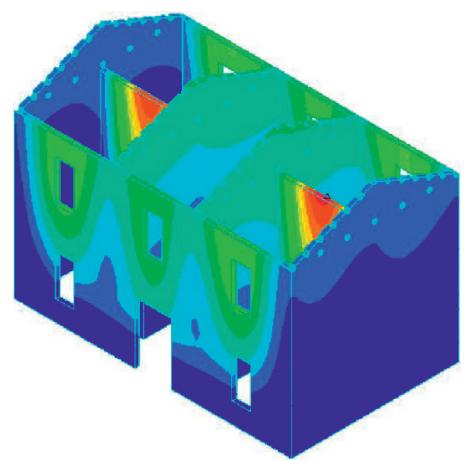

(a)
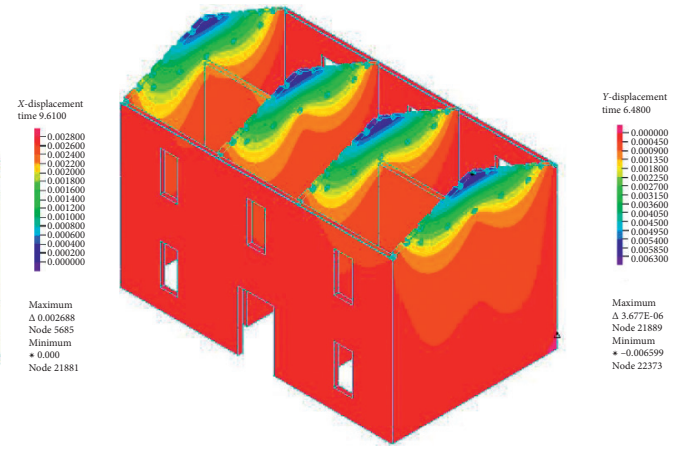

(b)

Figure 8: Cloud diagram of wall peak displacement under Taft earthquake with 7-degree fortification intensity. (a) $X$-direction. (b) $Y$-direction.

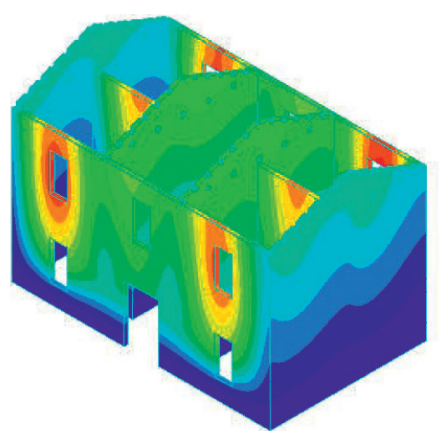

(a)
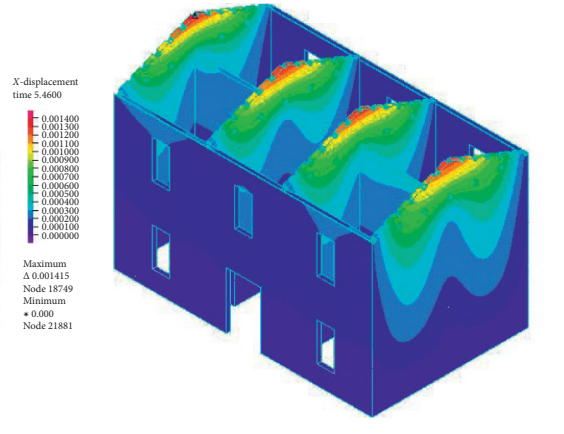

(b)

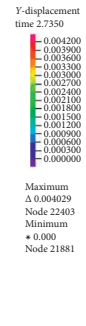

Figure 9: Cloud diagram of wall peak displacement under EL-Centro earthquake with 7-degree fortification intensity. (a) X-direction. (b) $Y$-direction.

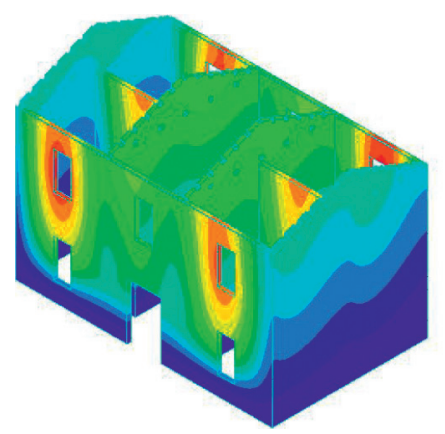

(a)
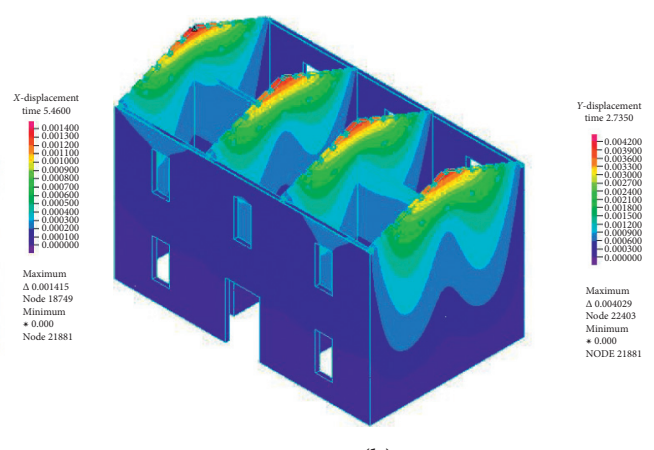

(b)

FIgUre 10: Cloud diagram of wall peak displacement under Loma Prieta earthquake with 7-degree fortification intensity. (a) X-direction. (b) $Y$-direction.

TABLE 4: Limiting values of interval displacement angle of masonry structure.

\begin{tabular}{lcccc}
\hline Seismic damage grade & Intact & Slight damage & Medium damage & Serious damage \\
\hline Limiting values of the interval displacement angle & $1 / 3000$ & $1 / 2000$ & $1 / 1100$ & $1 / 350$ \\
\hline
\end{tabular}


TABLe 5: Structure maximum displacement ( $\mathrm{mm}$ ), maximum interval displacement angle, and failure degree.

\begin{tabular}{lccrc}
\hline Seismic waves & $\begin{array}{c}\text { First-floor } \\
\text { displacement }\end{array}$ & $\begin{array}{c}\text { Second-floor } \\
\text { displacement }\end{array}$ & Maximum interval displacement angle & Failure degree \\
\hline Taft wave $(0.1 \mathrm{~g})$ & 0.57 & 3.4 & $5.549 \times 10^{-4}$ & Medium damage \\
Taft wave $(0.2 \mathrm{~g})$ & 0.739 & 6.622 & $1.154 \times 10^{-3}$ & Serious damage \\
EL-Centro wave $(0.1 \mathrm{~g})$ & 0.733 & 3.63 & $5.68 \times 10^{-4}$ & Medium damage \\
EL-Centro wave $(0.2 \mathrm{~g})$ & 1.261 & 8.599 & $1.439 \times 10^{-3}$ & Serious damage \\
Loma Prieta wave $(0.1 \mathrm{~g})$ & 0.611 & 2.27 & $3.25 \times 10^{-4}$ & Slight damage \\
Loma Prieta wave $(0.2 \mathrm{~g})$ & 0.931 & 4.044 & $6.104 \times 10^{-4}$ & Medium damage \\
\hline
\end{tabular}

TABLE 6: Maximum shear stress of wall bottom under each earthquake $(\mathrm{Pa})$.

\begin{tabular}{lcccc}
\hline Seismic intensity & Taft wave & EL-Centro wave & Loma Prieta wave & Average \\
\hline 6 degree & 182384 & 262260 & 229559 & 224734 \\
7 degree & 380692 & 468292 & 314878 & 387954 \\
\hline
\end{tabular}

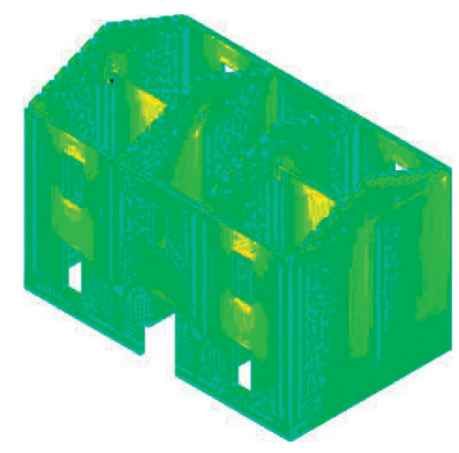

(a)
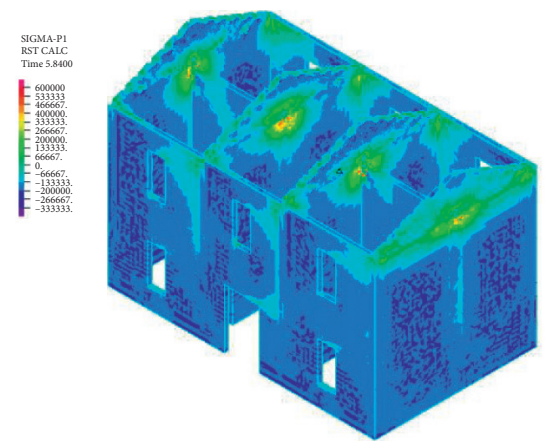

(b)

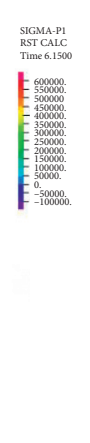

(a) $X$-direction. (b) $Y$-direction.

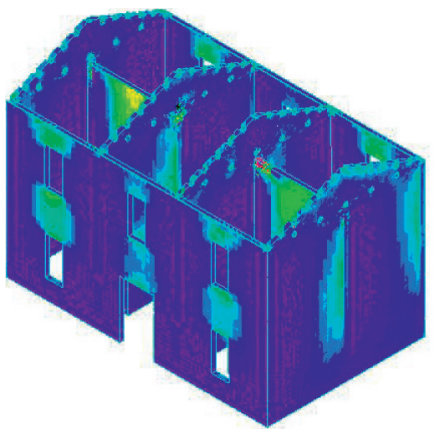

(a)
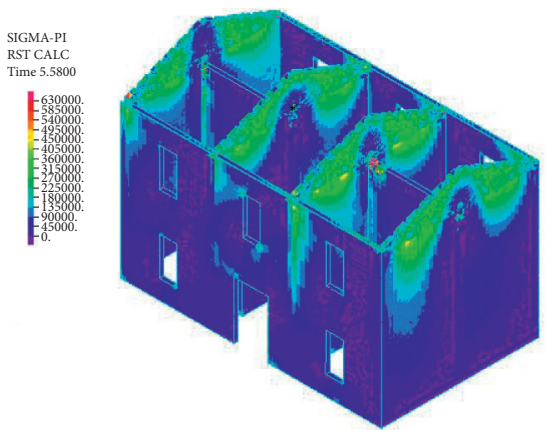

(b)

Figure 12: Cloud diagram of the maximum main tensile stress of the wall under EL-Centro earthquake (0.2 g). (a) $X$-direction. (b) $Y$-direction.

Under the action of a 6-degree earthquake, the average shear stress of wall bottom is $0.225 \mathrm{MPa}$. And under the action of a 7-degree earthquake, the average shear stress of wall bottom is $0.388 \mathrm{MPa}$, which has greatly exceeded the shear strength of clay brick by $0.11 \mathrm{MPa}$, indicating that there is a risk of shear failure or even collapse of local walls.

\section{Seismic Performance of Rural Buildings after Seismic Reinforcement}

It is found that, under the action of 6-degree $(0.1 \mathrm{~g})$ earthquake, the structure of brick-wood rural buildings in Jiangxi suffered medium damage. And under the action of 7 -degree $(0.2 \mathrm{~g})$ earthquake, the structure was seriously 


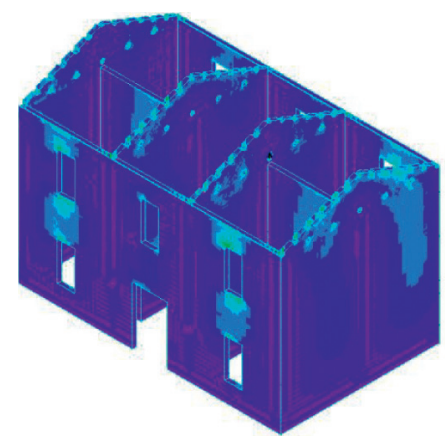

(a)

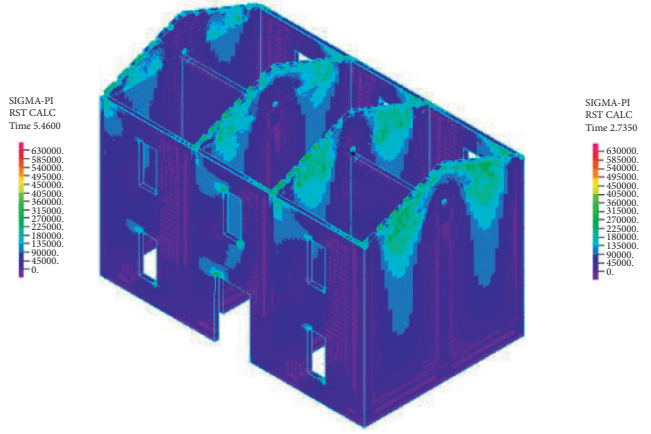

(b)

Figure 13: Cloud diagram of the maximum main tensile stress of the wall under the Loma Prieta earthquake (0.2 g). (a) $X$-direction. (b) $Y$-direction.

damaged. There is an obvious stress concentration phenomenon at locations, such as the intersection of horizontal and vertical walls, the opening, and the wall between windows, which are seismic weak spots. In a word, the seismic safety of the rural building is not enough to resist the strong earthquake load, which should add seismic reinforcement to improve the seismic performance of the rural house.

Most of the villages and towns in Jiangxi are distributed in mountainous areas, which are easy to use conventional materials and adopt simple construction methods to realize the reinforcement of rural houses. Therefore, referring to domestic and foreign research and the reinforcement methods that are easy to realize in local villages and towns $[10,11]$, the research proposes a reinforcement method of steel bar and wire mesh with cement mortar, adding steel mesh mortar surface layer on the outside of the house. Based on the needs of easy purchase and preparation of construction materials, cement mortar is used for the reinforcement of rural housing and add reinforced cement mortar strip at the junction of the vertical and horizontal walls of the external wall, the height of the first floor $(3.6 \mathrm{~m})$, and the eaves position to increase the integrity of the wall and improve the collapse ability of the house. By establishing the numerical model of the reinforced building, the effect of the reinforcement methods proposed in this paper is analyzed and compared.

The addition of reinforced mortar strips plays a role similar to ring beams and structural columns. It is an effective measure to strengthen the integrity of masonry buildings. It can restrain the development of cracks and greatly enhance the collapse resistance of the masonry walls. The house adopts the horizontal reinforced mortar belt as the ring beam at the elevation of the cornice (wall top), and the vertical reinforced mortar belt as the structural column at the junction of the vertical and horizontal walls of the outer wall of the house and the end of the wall.

The layout of the reinforced mortar belt is shown in Figure 14(a), and the mortar strength grade is M10. The height of the horizontal reinforced mortar belt is $240 \mathrm{~mm}$, the thickness is $50 \mathrm{~mm}$, the reinforcement is $2 \mathrm{HRB} 300$ steel bars with a diameter of $12 \mathrm{~mm}$, and the spacing between the steel bars is $200 \mathrm{~mm}$. The reinforcement of the horizontal reinforced mortar belt is shown in Figures 14(b)-14(e). The vertical reinforced mortar belt is arranged at the junction of the horizontal and vertical walls of the external wall and is mainly divided into "L-" and "T-" shaped vertical reinforced mortar belts. The "L-" shaped vertical reinforcement mortar belt uses two L-shaped wall-through steel wires to anchor the main reinforcement, and the "T-" shaped one uses U-shaped wall-through steel wires and in-line wall-through steel wires to anchor the main reinforcement (construction method: brick wall drilling, insert U Shaped steel wire, and bend and bind on another layer of the wall), the steel wire spacing is $500 \mathrm{~mm}$, and the wire diameter is not less than $4 \mathrm{~mm}$; see Figure 14(f) for details.

4.1. Structural Model after Reinforcement. In the reinforcement plan, the steel bars in the reinforced cement mortar are selected $\Phi 12$ steel bars and anchored through wall steel wires. The reinforced model and layout of steel bars are shown in Figure 15. In addition, the steel wire mesh mortar surface layer is modelled as a whole, and it is safe to use only the mortar layer material (without considering the parameters of steel wire mesh) for simulation.

4.2. Constitutive Relationship and Parameters of Reinforcement Materials. In this study, the constitutive relationship of cement mortar proposed by $\mathrm{Du}$ et al. [31] is selected, which is improved based on the concrete constitutive model and has passed the test verification. The constitutive relationship under compression is as follows (3):

$$
y= \begin{cases}2.1 x-1.2 x^{2}+0.1 x^{3}, & (x \leq 1), \\ \frac{x}{10(x-1)^{2}+x}, & (x \geq 1),\end{cases}
$$




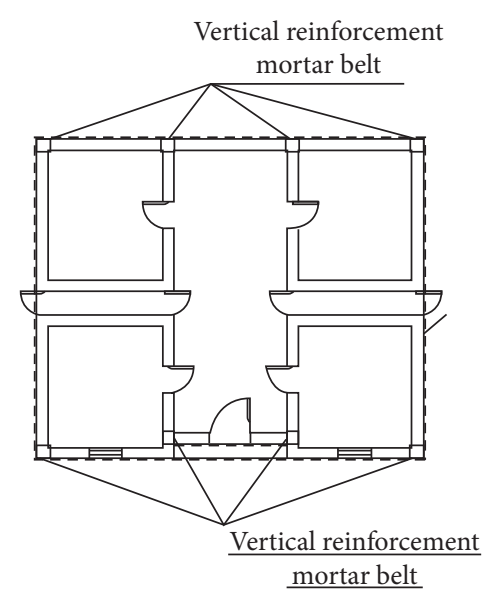

(a)

Reinforced mortar with Distribution of main reinforcement reinforcement

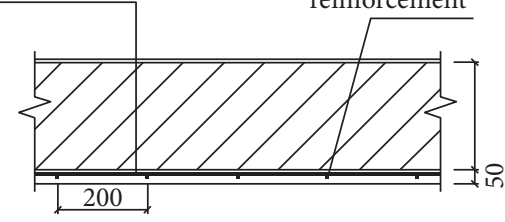

(c)

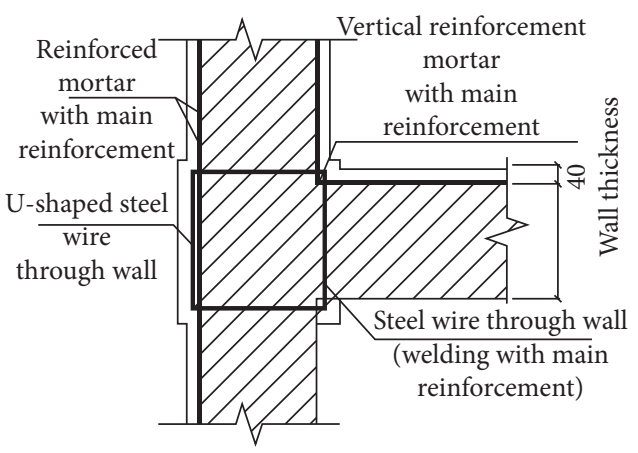

(e)

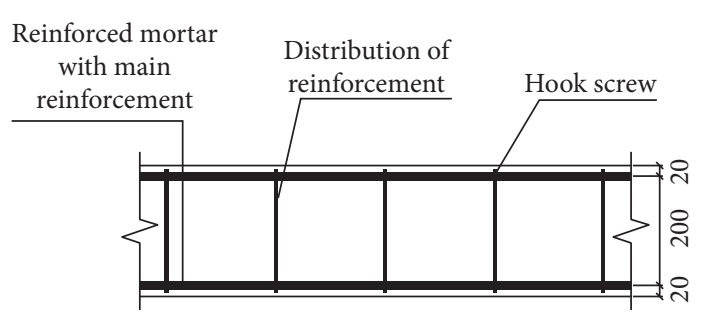

(b)

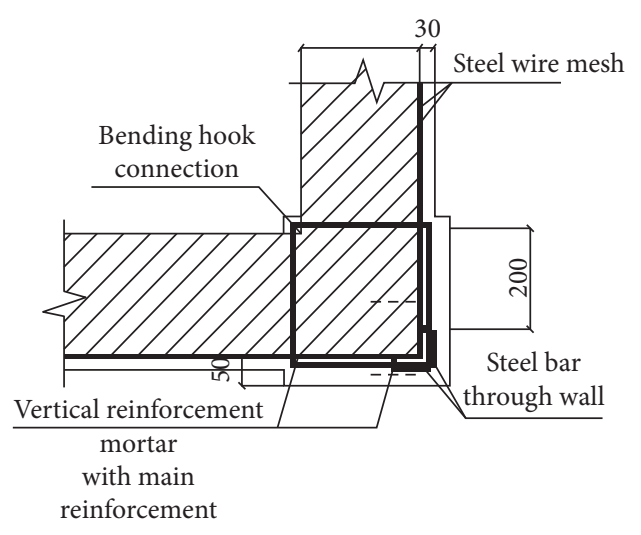

(d)

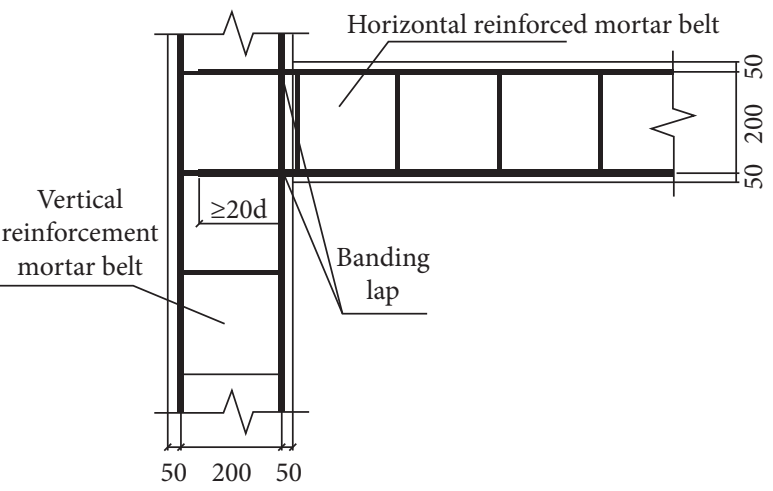

(f)

FIGURE 14: Schematic diagram of reinforced mortar belt. (a) Reinforced mortar belt layout drawing. (b) Brick masonry horizontal reinforcement mortar belt reinforcement map. (c) Sectional view of horizontally reinforced mortar belt of brick masonry. (d) Reinforcement diagram of "L"-shaped vertical reinforcement mortar belt. (e) Reinforcement diagram of " $\mathrm{T}$ "-shaped vertical reinforcement mortar with reinforcement. (f) Node diagram at the junction of vertically reinforced mortar belt and horizontally reinforced mortar belt.

where $x=\varepsilon / \varepsilon_{m}, y=\sigma / f_{m}, \varepsilon$ and $f$ are compressive stress and strain of cement, and $f_{m}$ and $\varepsilon_{m}$ are compressive strength and strain of cement mortar. Moreover, the Poisson ratio of cement mortar is 0.2 , and the elastic modulus is calculated according to formula (4). The strength of the reinforced mortar is $\mathrm{M} 10$, which can be obtained by calculation. The material parameters of mortar are shown in Table 7.

$$
E_{m}=1057 f_{2}^{0.84}
$$

\subsubsection{Constitutive Relationship of Steel Reinforcement.} The ideal elastic-plastic constitutive relationship is adopted for steel reinforcement, and the material parameters are shown in Table 8. 


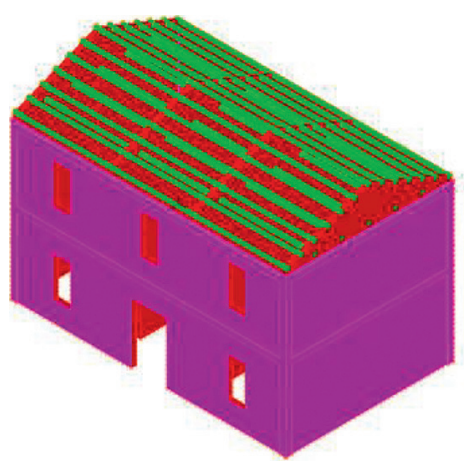

(a)

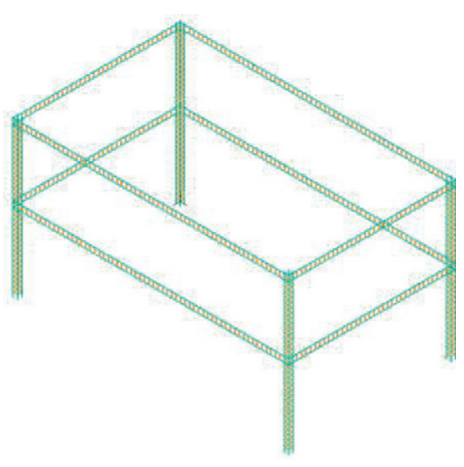

(b)

FIGURE 15: Numerical model of brick-wood structure after reinforcement. (a) House model. (b) Layout of steel bars.

TABLE 7: Material parameters of cement mortar.

\begin{tabular}{lcc}
\hline Elastic modulus $(\mathrm{MPa})$ & Poisson ratio & Density $\left(\mathrm{kg} / \mathrm{m}^{3}\right)$ \\
\hline 7312 & 0.2 & 2000 \\
\hline
\end{tabular}

TABLE 8: Steel material parameters.

\begin{tabular}{lccc}
\hline $\begin{array}{l}\text { Elastic modulus } \\
(\mathrm{MPa})\end{array}$ & $\begin{array}{c}\text { Poisson } \\
\text { ratio }\end{array}$ & $\begin{array}{c}\text { Yield strength } \\
(\mathrm{MPa})\end{array}$ & $\begin{array}{c}\text { Density }(\mathrm{kg} / \\
\left.\mathrm{m}^{3}\right)\end{array}$ \\
\hline 210000 & 0.3 & 300 & 7800 \\
\hline
\end{tabular}

\subsection{Numerical Results}

4.3.1. Modal Analysis of Reinforced Model. Through modal analysis, the first 6 natural vibration periods of the structure are obtained, as shown in Table 9. And as shown in Figure 16, the comparison shows that the natural vibration period of each order of the model after reinforcement is smaller than that of the original model, which indicates that the stiffness of the model is significantly improved after reinforcement, and the integrity of the building is improved.

4.3.2. Displacement Response of the Reinforced Model. Under the action of 6-degree and 7-degree earthquakes, the displacement response comparison of each layer before and after reinforcement is shown in Figures 17-19. Table 10 summarizes the maximum displacement, interval displacement angle, and damage degree of the reinforcement model under the action of an earthquake. The analysis found the following.

The maximum displacement of the structure after reinforcement is significantly reduced, which shows that the reinforcement method can effectively improve the seismic performance of the building and the displacement response of the structure under earthquake action.

According to the statistics of the interval displacement angle shown in Table 10, under the action of a 6-degree earthquake, the reinforced structure only suffered slight damage. Under the action of the 7-degree earthquake, the
TABLE 9: The first 6 natural vibration periods.

\begin{tabular}{lcccccc}
\hline Vibration & $\begin{array}{c}1 \\
\text { order }\end{array}$ & $\begin{array}{c}2 \\
\text { order }\end{array}$ & $\begin{array}{c}3 \\
\text { order }\end{array}$ & $\begin{array}{c}4 \\
\text { order }\end{array}$ & $\begin{array}{c}5 \\
\text { order }\end{array}$ & $\begin{array}{c}6 \\
\text { order }\end{array}$ \\
\hline $\begin{array}{l}\text { Frequency } \\
\text { (Hz) }\end{array}$ & 7.97 & 9.234 & 9.669 & 9.681 & 9.747 & 10.05 \\
Period (s) & 0.125 & 0.108 & 0.103 & 0.103 & 0.103 & 0.100 \\
\hline
\end{tabular}

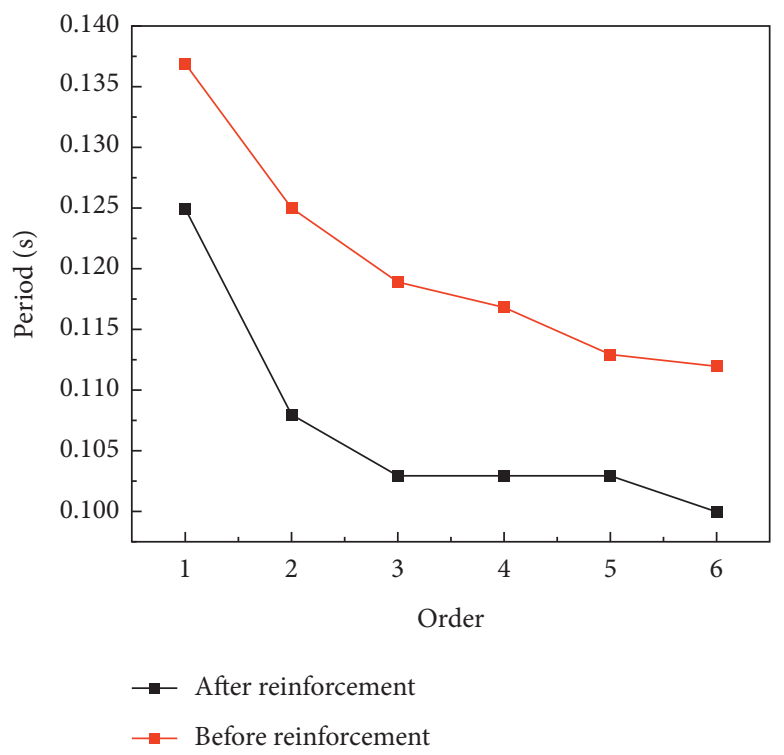

FIGURE 16: Comparison of natural vibration periods before and after reinforcement.

structure produces medium damage, which is significantly improved compared with the unreinforced structure. In the reinforced model, the maximum displacement still appears at the top of the gable. It can be seen that, under the action of an earthquake, due to the purlin roof structure, timber purlin and top of the gable are easy to be separated or collide, resulting in large displacement or damage. Therefore, in the reinforcement of the building, the wall should be added with other structures to 


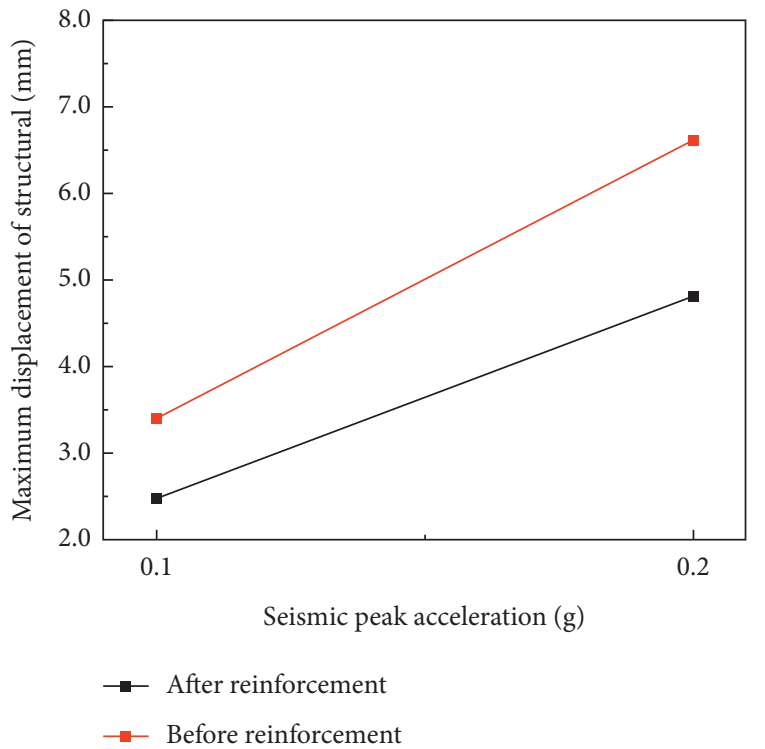

Figure 17: Comparison of the maximum displacement of the structure under Taft earthquake.

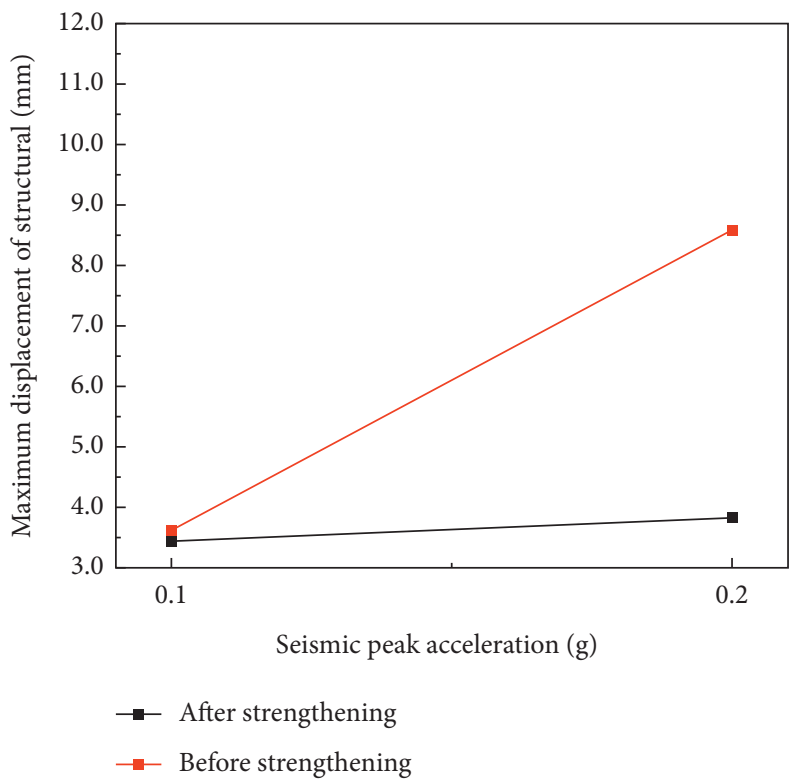

Figure 18: Comparison of the maximum displacement of the structure under EL-Centro earthquake.

strengthen the connection between the wall and the timber purlin, to form a whole, and to further improve the seismic performance of the house. In this model, the stable connection between the timber purlin and the wall is considered.

4.3.3. Stress Response of the Reinforced Model. Taking the stress response of the reinforced structure under the action of EL-Centro seismic wave as an example, the comparison of main tensile stress and shear stress before and after reinforcement is shown in Figures 20 and 21. It was found that, before reinforcement, there was an obvious stress concentration in the wall near the opening and between the windows. After the reinforcement, the wall stress was significantly improved, and the shear stress of the gable and so on was greatly reduced.

Figure 22 shows the stress cloud diagram shared by the mortar layer and masonry structure after reinforcement. It can be found that, under the seismic action, the reinforced surface layer shares the main shear stress and the main tensile stress, which effectively improves the stress concentration at the opening and the intersection of horizontal and vertical walls. Adding reinforced mortar strips can also effectively improve the overall shear stress and local shear stress concentration of the wall. 


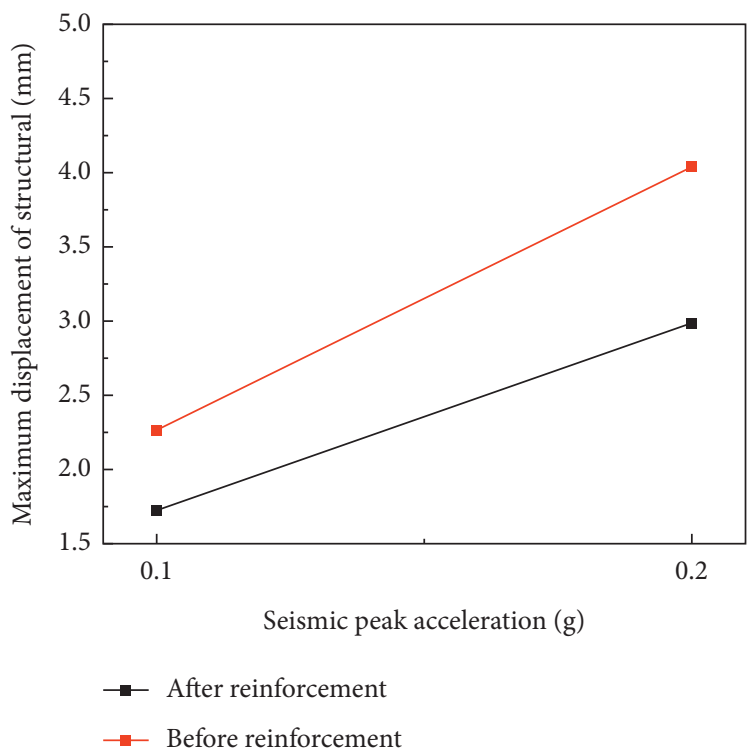

Figure 19: Comparison of the maximum displacement of the structure under the Loma Prieta earthquake.

TABLE 10: Maximum displacement ( $\mathrm{mm})$, maximum interval displacement angle, and failure degree of the structure after reinforcement.

\begin{tabular}{lcccc}
\hline Seismic wave & First-floor displacement & Second-floor displacement & Maximum interval displacement angle & Failure degree \\
\hline Taft wave $(0.1 \mathrm{~g})$ & 0.511 & 2.472 & $3.845 \times 10^{-4}$ & Slight damage \\
Taft wave $(0.2 \mathrm{~g})$ & 0.519 & 4.818 & $8.429 \times 10^{-4}$ & Medium damage \\
EL-Centro $(0.1 \mathrm{~g})$ & 0.594 & 3.459 & $5.618 \times 10^{-4}$ & Medium damage \\
EL-Centro $(0.2 \mathrm{~g})$ & 0.819 & 3.844 & $5.931 \times 10^{-3}$ & Medium damage \\
Loma Prieta $(0.1 \mathrm{~g})$ & 0.4393 & 1.726 & $2.523 \times 10^{-4}$ & Slight damage \\
Loma Prieta $(0.2 \mathrm{~g})$ & 0.770 & 2.990 & $4.353 \times 10^{-4}$ & Slight damage \\
\hline
\end{tabular}

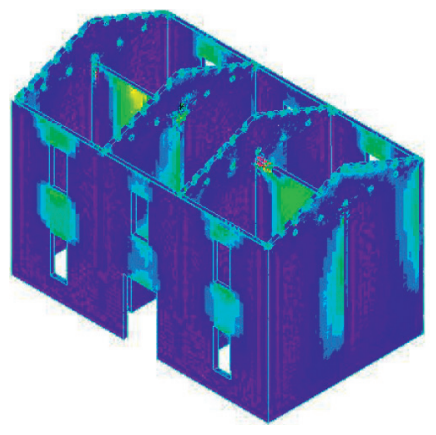

(a)
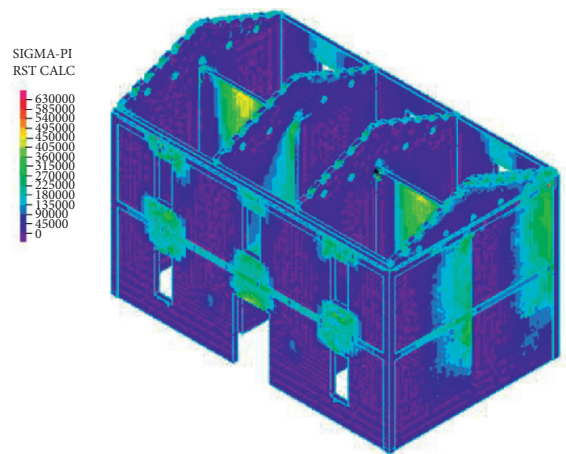

(b)

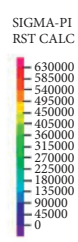

Figure 20: Comparison of main tensile stress of the structure before and after reinforcement. (a) Original structure (before reinforcement). (b) Structure after reinforcement. 


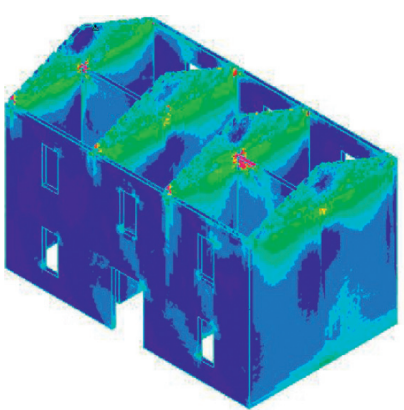

(a)
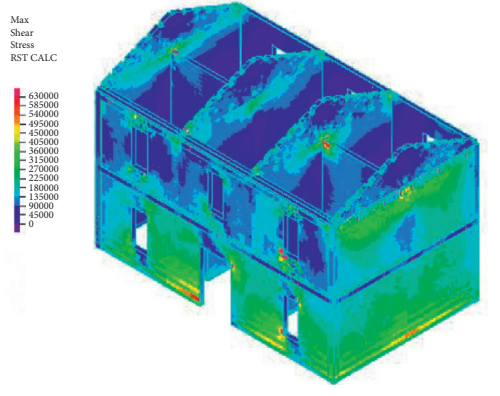

(b)

FIgURE 21: Comparison of shear stress of the structure before and after reinforcement. (a) Original structure. (b) Structure after reinforcement.

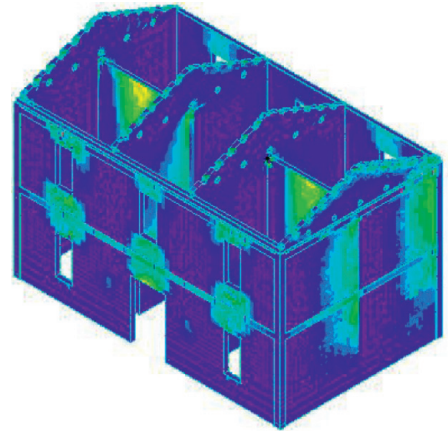

(a)

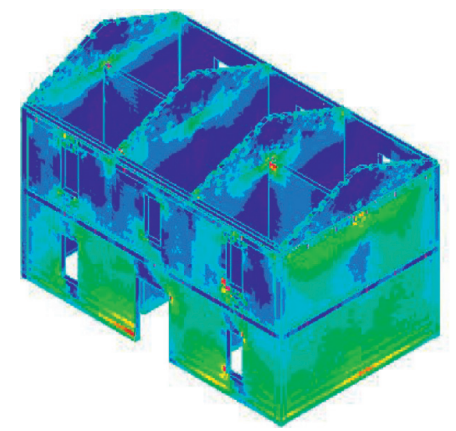

(c)
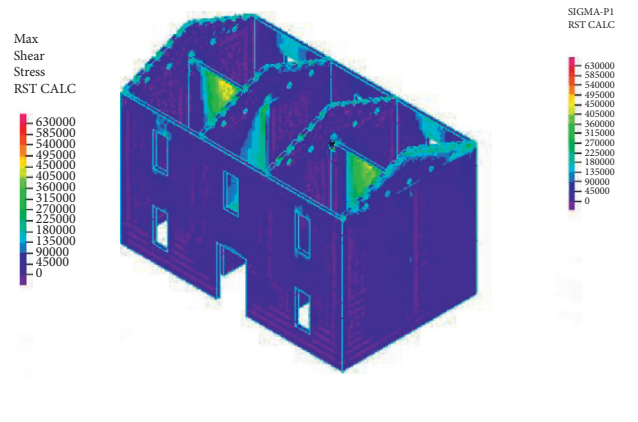

(b)
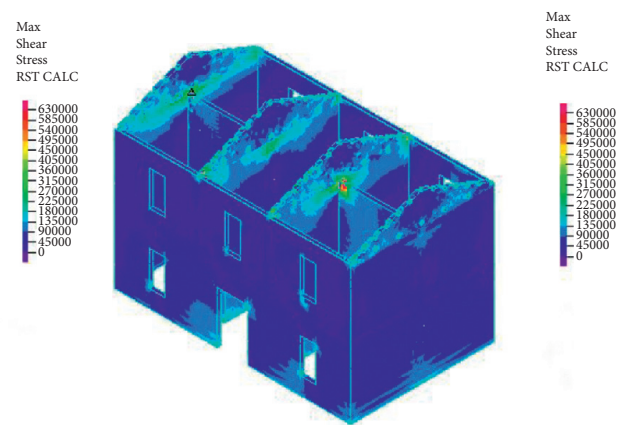

(d)

Figure 22: Comparison of stress cloud diagram between the mortar layer and masonry for structures after reinforcement. (a) Main tensile stress of mortar layer. (b) Main tensile stress of masonry. (c) Shear stress of mortar layer. (d) Shear stress of masonry.

\section{Conclusion}

Based on the earthquake investigation and numerical simulation, it is found that the seismic capacity of traditional brick-wood rural buildings in South China is insufficient. Under the earthquake action of 6-degree and 7degree fortification intensity in China, the structures raise plastic deformation as the increase of the peak ground acceleration. The structure has medium damage under seismic load with 6-degree fortification intensity. The structure is seriously damaged under seismic load with 7degree fortification intensity. Cracks often appeared at the contact position between timber purlin and gable, resulting in the maximum $Y$-direction displacement. This is mainly due to the nonconnection of the traditional purlin roof structure, which is not conducive to the structural seismic resistance. In addition, the weak spots occurred in the opening of the wall, the wall between windows, the top of the inner transverse wall, and the junction of the transverse and longitudinal walls, and there is an obvious stress concentration phenomenon.

After reinforcement with a steel bar and wire mesh with cement mortar or other structures, the seismic response analysis shows that the structure displacement and stress response significantly reduced. Under the action of a 6-degree earthquake, the reinforcement model was only slightly damaged; under the action of a 7-degree earthquake, the reinforcement model has medium damage, and the damage generally occurs at 
the contact position of the gable top with the timber purlin. This type of damage is mostly caused by the purlin roof structure. As far as the exterior wall is concerned, the original stress concentration position is transferred to the reinforced surface after reinforcement, and the damage mostly occurs in the reinforced surface. The overall stress and displacement of the wall are improved. At the same time, considering that the reinforcement effect of steel mesh has not been considered in the model, the simulation results tend to be conservative. Therefore, the reinforced buildings can ensure the safe use of the buildings under the action of 6- and 7-degree earthquakes.

Moreover, under the earthquake action, the stress concentration still exists in the junction of the inner and outer wall and the window and door holes after reinforcement. Therefore, these parts of the traditional brickwood rural buildings should be regarded as the main objects for seismic reinforcement.

\section{Data Availability}

The data used to support the findings of this study are available from the corresponding author upon request.

\section{Conflicts of Interest}

The authors declare that there are no conflicts of interest regarding this study.

\section{Acknowledgments}

This work was financially supported by the National Science Foundation of China (Grant no. 51868048) and China Earthquake Administration Basic Research Project (Grant no. 2018D18).

\section{References}

[1] L. I. Gang, X. Liu, and H. Li, "Seismic damage investigation and analysis on rural buildings in Wenchuan earthquake," Journal of Dalian University of Technolgy, vol. 49, no. 5, pp. 724-730, 2009.

[2] G. Jia, Z. Yuan, X. Zhong, and K. Xia, "Study on characteristics of seismic damage to rural self-built brick masonry houses at different intensity zones," World Earthquake Engineering, vol. 26, no. 4, pp. 724-730, 2010.

[3] Q. Su and C. Liu, "Analysis of characteristic ratio of the seismic wall of brick masonry buildings," Journal of Building Structures, vol. 38, no. 12, pp. 163-169, 2017.

[4] X. Liu, H. Zhang, and J. Liu, "Study on strengthening the seismic performance of the brick building with reinforced concrete structural column," Building Structure, vol. 2, no. 6, pp. 47-55, 1981.

[5] C. Cheng, Y. Zheng, and M. Wu, "Experimental study on a single-story reinforced masonry model house by vibration table," Building Structure, vol. 35, no. 9, pp. 28-33, 2005.

[6] X. Li, "Several new forms of masonry building in the abroad," Architectural Technology, vol. 19, no. 2, pp. 114-115, 1992.

[7] A. Ahamad, O. Ambrose, and M. Chukwunenye, "Compression behaviour of concrete masonry prisms," Jamal of Structural Engineering, vol. 112, no. 3, pp. 605-613, 1986.

[8] J. J. Bommer, G. Magenes, J. Hancock, and P. Penazzo, "The influence of strong-motion duration on the seismic response of masonry structures," Bulletin of Earthquake Engineering, vol. 2, no. 1, pp. 1-26, 2004.

[9] P. B. Lourenço, N. Mendes, L. F. Ramos, and D. V. Oliveira, "Analysis of masonry structures without box behavior," International Journal of Architectural Heritage, vol. 5, no. 4-5, pp. 369-382, 2011.

[10] B. Zhu, M.-H Wu, and Z. Jiang, "Study for seismic performance of masonry wall reinforced by steel bar-mortar method," Earthquake Engineering and Engineering Vibration, vol. 4, no. 1, pp. 70-81, 1984.

[11] X. Zhou, W. Xie, and J. Jiang, "Application study for seismic performances of existing masonry wall reinforced by steel barmortar crossed strip method," Building Structure, vol. 49, no. 5, pp. 1-8, 2019.

[12] L. Lin and L. Ye, "Experimental investigation on masonry wall strengthened with FRP," Building Structure, vol. 35, no. 3, pp. 21-27, 2005.

[13] S. Shang and M. Lei, "Test study on seismic behavior and finite element analysis of row lock wall strengthened with HPFL," Earthquake Engineering and Engineering Vibration, vol. 33, no. 4, pp. 218-227, 2013.

[14] M. Deng, X. Gao, X. Liang, and X. M. Fan, "Experimental investigation on seismic behavior of brick wall strengthened with ECC splint," Engineering Mechanics, vol. 30, no. 6, pp. 168-174, 2013.

[15] Y. Wang, Q. Yao, and Z. Wang, "Test on brick walls strengthened by the composite cover of high strength wire cable mesh and polymeric mortar," Building Structure, vol. 35, no. 8, pp. 36-40, 2005.

[16] M. Deng, S. Yang, and X. Liang, "Experimental studies on seismic behavior of confined masonry walls strengthened with single HDC layer," China Civil Engineering Journal, vol. 51, no. 4, pp. 10-19, 2018.

[17] D. Ge, X. Chen, and W. Li, "Application of progressivecollapse numerical simulation of masonry structures under earthquake action," Building Structure, vol. 46, no. 17, pp. 88-92, 2016.

[18] B. Sun and H. Deng, "Study on seismic behavior of bottom frame structure building," Journal of Building Structures, vol. 36, no. s2, pp. 131-137, 2015.

[19] J. Hua, T. Wu, and M. Jiang, "Numerical analysis of seismic behaviors of masonry structures in village buildings during strong earthquakes," China Earthquake Engineering Journal, vol. 39, no. 1, pp. 52-57, 2017.

[20] T. Wu, H. Wang, and M. Yi, "Dynamic characteristics of masonry structures in villages and towns," China Earthquake Engineering Journal, vol. 38, no. 6, pp. 877-882, 2016.

[21] R. Yu, Z. Xie, and L. Peng, "Effect of masonry strength on seismic performance of self-built dwellings," Earthquake Engineering and Engineering Vibration, vol. 33, no. 11, pp. 6-11, 2014.

[22] Q. Zhou, Q. Min, and Y. Xiong, "Seismic performance analysis of existing typical rural buildings in Jiangxi," Journal of Natural Disasters, vol. 27, no. 1, pp. 96-105, 2018.

[23] G. Zhao, Y. Ma, and X. Chen, "Vulnerability analysis of performance-based seismic design criteria for rural buildings," China Civil Engineering Journal, vol. 47, no. 9, pp. 1-8, 2014.

[24] X. Yao, B. Sun, and Y.-K. Chen, "Elastic-plastic finite element analysis of typical brick-wood rural buildings underground motions," China Earthquake Engineering Journal, vol. 40, no. 1, pp. 32-40, 2018. 
[25] G. Liu, The Research on the Basic Mechanical Behavior of Masonry Structure, Hunan University, Changsha, China, 2005.

[26] T. Wu and R. Hou, "Experimental studies on elastic modulus and the Poisson ratio of fired perforated brick masonry," Building Structure, vol. 42, no. 12, pp. 117-138, 2012.

[27] Y. Ding, Study on Anti-seismic Performance of Brick Structures in Western Rural Areas, Xi'an University of Architecture and Technology, Xi'an, China, 2015.

[28] Y. Yang, L. Yang, and Y. Gao, "Method of damage prediction for existing militia-story brick buildings and its reliability," Earthquake Engineering and Engineering Vibration, vol. 2, no. 3, pp. 75-86, 1982.

[29] B. Chen, D. Wang, S. Chen, and S. Hu, "Influence of site factors on offshore ground motions: observed results and numerical simulation," Soil Dynamics and Earthquake Engineering, vol. 145, Article ID 106729, 2021.

[30] L.-Y. Xu, S. Cheng-Xiang, W.-Y. Chen, F. Cai, Y. Y. Li, and G.-X. Chen, "Liquefaction-induced settlement of the pile group under vertical and horizontal ground motions," Soil Dynamics and Earthquake Engineering, vol. 144, Article ID 106709, 2021.

[31] X. Du, Y. Wang, D. Lu, and C. Ma, "Study on static and dynamic stress-strain in a relationship of cement mortar material," China Journal of Civil Engineering, vol. 43, no. s2, pp. 119-126, 2010. 